\title{
Portugueses, americanos, brasileiros: identidades políticas na crise do Antigo Regime luso-americano*.
}

Portuguese, Americans, Brazilians:

political identities during the crises

of the Luso-American Ancien

Régime

\section{João Paulo Garrido Pimenta}

Professor do Departamento de História da Universidade de São Paulo.
* Uma primeira versão deste texto foi apresentada no Primer Encuentro de Historiadores de Brasil y de Colombia, realizado em Bogotá em agosto de 2005. Para transformá-lo em artigo, recebi críticas e sugestões de María Tereza Calderón e Luiz Geraldo Silva, a quem devo meus agradecimentos.

\section{Resumo}

Este artigo realiza um apanhado geral do desenvolvimento histórico das identidades políticas presentes na América portuguesa, enfatizando mais especificamente as referências ligadas a uma idéia de América. A idéia central aqui sustentada é a de que uma identidade luso-americana foi, ao mesmo tempo, indício revelador do processo de crise do Antigo Regime português a partir de meados do século XVIII, bem como fator decisivo para a constituição do projeto de separação política entre Brasil e Portugal, consumada em 1822.

\section{Abstract}

This text presents a general appraisal of the political identities' historical development in Portuguese America, stressing the references concerning the idea of an "America". A Luso-American identity was both a revealing trace of the process of the Portuguese Ancien Régime crises (from the mid Eighteenth Century on), and also a decisive factor towards the development of a project of political separation between Brazil and Portugal, that came to life on 1822.

\section{Palavras-chave}

América espanhola, Colônia, Independência, nação, identidade regional, vocabulário político

\section{Keywords}

Spanish America, Colony, Independence, nation, regional identity, political vocabulary 
Revérbero Constitucional Fluminense n.19, 19/03/1822.

2

Valho-me sobretudo das considerações de Reinhardt Koselleck. "Historia conceptual e historia social." Futuro pasado: para uma semântica de los tiempos históricos. Barcelona, Paidós, 1993, p.105-126; também J. G. A. Pocock. "0 conceito de linguagem e o métier d'historien". Linguagens do ideário político. São Paulo, Edusp, 2003, p.63-82.

3

Por "identidades coletivas" me refiro, genericamente, a expressões de reconhecido e abrangente uso coevo, utilizadas para auto-identificação de grupos sociais e/ou para identificação desses grupos por terceiros, pautadas por critérios de variável abrangência e natureza. Ao longo do texto, procurarei pontuar momentos em que tais expressões adquirem, no universo luso-americano, sentidos especificamente políticos, ou seja, passam a ser utilizadas em referência a formas de organização política dos grupos em questão. Parto do pressuposto de que os estudos históricos das identidades coletivas devem tomá-las em dupla dimensão: como indicadores de realidades sociais, e como elementos propiciadores de reconfigurações dessas mesmas realidades.
Em um artigo dedicado a louvar a posição de destaque ocupada pela América no conjunto dos domínios portugueses, o editor do Revérbero Constitucional Fluminense, um dos mais importantes periódicos editados no Brasil, afirmava, em março de 1822, que "a Liberdade é congênita com o Brasileiro; o horror ao Despotismo é inato nos Americanos".1 Resultado de um desenvolvimento histórico recente, a associação entre Brasil, América e liberdade tipificava a agudização da prolongada crise que, abalando os alicerces da unidade política da nação portuguesa desde a instalação da Corte no Rio de Janeiro em 1808, fazia surgir, em 1822, a alternativa da separação de destinos entre Portugal e Brasil. No entanto, ainda que essa alternativa emergisse com força, em meados de 1822 ela não era absoluta, e nada garantia, aos envolvidos nas lutas políticas em curso, que ela finalmente sairia vitoriosa. $\mathrm{Na}$ época do Revérbero, os termos brasileiros e americanos, longe de serem expressões corriqueiras e consensuais, eram novidades, ao menos no que toca aos seus sentidos e ao seu caráter de potencial arma politica.

Minha proposta é caracterizar dimensões da crise do Antigo Regime português na América por meio de uma análise da configuração de expressões identitárias cujos conteúdos políticos, ao mesmo tempo em que passaram traduziam anseios de separação entre Brasil e Portugal, contribuiram, nas primeiras duas décadas do século XIX, para a própria consecução de tal projeto. Nesse movimento, sublinharei mais especificamente as condições de emergência de uma identidade nacional brasileira, mostrando sua profunda associação a uma idéia política de América. Em termos metodológicos considerarei, portanto, que todo e qualquer universo vocabular deve ser sempre interpretado pelos historiadores numa dupla e simultânea dimensão. Em primeiro lugar, como tradução discursiva de realidades sociais, ou seja, como indicativo de dimensões dessas realidades; em segundo lugar, como um conjunto de ferramentas de transformação social capazes de reconfigurar a própria realidade que as produz. ${ }^{2}$

Ao cabo do período aqui analisado, a crise do Antigo Regime fará surgir, na América portuguesa, uma situação aparentemente desconcertante. Afinal, a partir da independência do Brasil, consumada em 1822, uma nação brasileira começará a dar seus primeiros passos legitimada por uma imprescindivel auto-imagem de diferenciação da comunidade por ela referida em relação a todas as demais existentes (e nesse sentido, o Brasil surge como um corpo político nacional singular e distinto, sobretudo, em relação àqueles que, mais ou menos pela mesma época, se formavam na sua vizinhança continental). Contudo, a produção dessa auto-imagem, conforme veremos a seguir, teve que galgar um passo anterior: a diferenciação do Brasil em relação a Portugal, na qual a concepção de um Brasil "nãoeuropeu", isto é, americano, ofereceria uma base poderosa de legitimação de seu projeto de independência.

Ao longo dos séculos XVI, XVII e XVIII, a história da colonização portuguesa da América engendrou um estado de coisas cuja complexidade tinha plena correspondência no plano das identidades coletivas. ${ }^{3}$ Ao mesmo tempo em que desempenhara um papel de agente da expansão dos domínios do rei de Portugal e da religião cristã, o elemento português no Novo Mundo acabava por reproduzir valores e atitudes que, aos olhos do historiador, configuram um sistema de relações econômicas e sociais de 
De diferentes maneiras, essa necessária ambigüidade das feições assumidas pelas formas sociais e econômicas européias nos espaços coloniais - especificamente nos luso-americanos - têm sido presença constante na historiografia brasileira. Três autores cujos trabalhos, em diferentes perspectivas, merecem menção são: Sérgio Buarque de Holanda - Raízes do Brasil. 12a ed. Rio de Janeiro, José Olympio, 1978; Florestan Fernandes. A sociedade escravista no Brasil. Circuito Fechado. São Paulo, Hucitec, 1976, p.11-63; e Fernando Novais. Condições da privacidade na colônia. História da vida privada no Brasil, t.I. São Paulo, Companhia das Letras, 1997.

István Jancsó \& João Paulo G. Pimenta. "Peças de um mosaico (ou apontamentos para o estudo da emergência da identidade nacional brasileira)." In: Carlos G. Mota (org.) - Viagem incompleta: a experiência brasileira (1500-2000). São Paulo, Senac, 2000, p.126-175.

6

István Jancsó. "Independência, independências." In: Independência: história e historiografia. São Paulo, Hucitec/Fapesp, 2005, p.22.

\section{7}

Jancsó \&t Pimenta, "Peças de um mosaico...", cit, p.136-138. Para os diferentes usos e sentidos do termo "nação", coexistentes no mundo do Antigo Regime e no qual o caso português não configura exceção em meio a um panorama de grande diversidade e complexidade, vide o excelente estudo de José Carlos Chiaramonte. "Metamorfoses do conceito de nação durante os séculos XVII e XVIII". Jancsó (org.) - Brasil: formação do Estado e da nação. São Paulo, Hucitec/Fapesp/Editora Unijuí, 2003, p.61-91.

Jancsó \& Pimenta, "Peças de um mosaico..." p.136-137. matriz européia. No ambiente colonial, tais valores e atitudes necessariamente se metamorfoseavam e produziam novas sínteses, do que resultava que o universo luso-americano, ao mesmo tempo em que tinha sua lógica histórica determinada por sua inserção num conjunto de relações de ordem sistêmica e de abrangência tendencialmente planetária - a "economiamundo" européia -, era, em si mesmo, profundamente específico. ${ }^{4}$ Daí a existência de um substrato identitário da colonização portuguesa que, ao configurar identidades coletivas especificas nos espaços coloniais, reproduzia o próprio esquema geral de constituição do Império. ${ }^{5}$

Como muito bem nos adverte István Jancsó, "a longa história da interface entre metrópole européia e suas colônias americanas não foi linear", sendo que a própria construção do Antigo Regime português na América - e, por extensão, do jogo das identidades coletivas no seu bojo - se deu por meio de articulações entre espaços sociais distintos, obedecendo a ritmos distintos sem, entretanto, romper com a lógica estruturante que the conferia sentido. ${ }^{6}$ Obedecendo a tal lógica, durante três séculos, o componente fundamental desse substrato identitário foi a identificação da grande comunidade integrada por todos os súditos do mesmo rei (de Portugal), gravitando em torno de sua imagem, da dinastia e da sede da monarquia, portadores - ao menos oficialmente - da religião católica. Estivessem onde estivessem, independentemente de relações horizontais e verticais recíprocas, todos eles formavam aquilo que, à própria época, era costume se designar por nação portuguesa. ${ }^{7}$

A nação portuguesa era a mais estável e abrangente identidade coletiva em vigência no mundo português, identificando não apenas a ampla coletividade de súditos do mesmo monarca, mas, igualmente, um espaço de governo e de jurisdição. Identidade, portanto, inclusive de caráter político, e que unificava e homogeneizava a profunda heterogeneidade - não somente política - inerente à natureza do Império. Mas essa heterogeneidade, ainda que subordinada no plano identitário à nação portuguesa, não deixava de se manifestar nesse mesmo plano. Colonos portugueses da América eram, por exemplo, paulistas, baienses ou pernambucanos, a depender de qual fosse a base territorial específica (e não política) de sua existência no conjunto do Império. No entanto, se o português de São Paulo se identificava e era identificado como "paulista" diante do português de Pernambuco - o "pernambucano" - ambos eram, quando confrontados com espanhóis ou holandeses, simplesmente "portugueses".8

Desse modo, a coexistência de referencias identitárias de distinta abrangência, portadoras ou não de conteúdos políticos, espelhava com clareza a natureza da constituição da "nação portuguesa", no bojo da qual os domínios do monarca só possuiam feições reconhecidamente capazes de gerar identificações coletivas especificas na medida em que estas não transcendessem a lógica geral do sistema. E foi assim que, a esses dois tipos de identidades coletivas, somar-se-ia uma terceira, de abrangência intermediária: a americana. Nos primeiros trinta anos de presença portuguesa no continente, a simples identificação nominal das terras a serem colonizadas se mostrara pouco propícia a consensos: "Vera Cruz", "Terra dos Papagaios", "Terra de Gonçalo Coelho" e "Santa Cruz" são algumas das palavras encontradas nos cronistas e documentos da época. No início do século XVII, quando "Terra de Santa Cruz" e "Brasil" dividiam as preferências e protagonizavam uma curiosa disputa entre nomenclaturas de cunho, respectivamente, místico e comercial - a terra colocada sob a bênção da cristandade 
Laura de Mello e Souza. "0 nome do Brasil". Revista de História n.145. São Paulo, Departamento de História/USP, 2.0 sem.2001, p.61-86. A autora esclarece que a designação "Brasil" aparece pela primeira vez, possivelmente, no Esmeraldo de Situ Orbis, de Duarte Pacheco Pereira (escrito por volta de 1505-1508), derivado de variantes como Bracir, Bracil, Brazille, Bersil, Braxili, Braxill, Bresilge, utilizadas entre 1351 e 1500 para designar uma mitológica região desconhecida dos europeus que poderia se localizar em muitos lugares diferentes (Souza, "O nome do Brasil", cit., p.66-68; também Sérgio Buarque de Holanda - Visão do paraíso: os motivos edênicos no descobrimento e colonização do Brasil. São Paulo, Brasiliense/ Publifolha, 2000).

10

Souza, op. cit., p.73.

11

Jancsó \&t Pimenta, "Peças de um mosaico...", cit., p.138-139.

12

Fernando Novais - Portugal e Brasil na crise do Antigo Sistema Colonial (1777-1808). 4a.ed. São Paulo, Hucitec, 1986, cap.l; Laura de Mello e Souza \& Maria Fernanda Bicalho 1680-1720: o império deste mundo. São Paulo, Companhia das Letras, 2000.

13

Stuart Schwartz - Segredos internos:engenhos e escravos na sociedade colonial, 1550 1835. São Paulo, Companhia das Letras, 1988; Luiz Felipe de Alencastro - 0 trato dos viventes: formação do Brasil no Atlântico sul, séculos XVI-XVII. São Paulo, Companhia das Letras, 2000.

14

Luciano Figueiredo. "0 império em apuros: notas para o estudo das alterações ultramarinas e das práticas políticas no Império colonial português, séculos XVII e XVIII". Júnia Furtado (org.) - Diálogos oceânicos: Minas Gerais e as novas abordagens para uma história do Império ultramarino português. Belo Horizonte, Edufmg, 2001.

\section{5}

Nuno Marques Pereira - Compêndio Narrativo do Peregrino da América (1728), citado por Souza, "0 nome do Brasil", cit., p.79-80. contra a terra fornecedora do pau-de-tinta ${ }^{9}$ - Ambrósio Fernandes Brandão escreveu, em seu Diálogo das grandezas do Brasil (1618), que "essa província do Brasil é conhecida no mundo todo com o nome de América".10 Começava, assim, a surgir uma nova forma de identidade portuguesa mas que, à exemplo dos "paulistas", "baienses" ou "pernambucanos", não seria capaz, de início, de portar conteúdos políticos. ${ }^{11}$

Portanto, no mundo colonial, o substrato identitário da colonização portuguesa era marcado pela coexistência de identidades coletivas múltiplas e de variada abrangência, cuja interelação se desenvolvia seguindo os padrões mais amplos de reprodução e complexificação do Império Português. Tal dinâmica resultava, necessariamente, em conflitos de diversa natureza e que desempenharão, a partir e ao longo do século XVIII, um papel crucial nas redefinições operadas no plano das identidades coletivas, que por seu turno se constituirão, conforme veremos adiante, em ferramentas capazes de reconfigurar a própria realidade que as criava.

Contestações abertas eram um elemento perene no cenário colonial, porque emergidas de situações inerentes à sua constituição histórica. Espaços sócio-econômicos primordialmente agrários, submetidos a determinações impostas por um cenário mundial de competição político-militar que os tornava vulneráveis a invasões externas, ${ }^{12}$ bem como a tentativa metropolitana de governar à distância e de transplantar para a América instituições e valores europeus, tudo isso envolvendo uma ordem social estamental profundamente hierarquizada, escravista e violenta que demandava permanente reprodução, ${ }_{13}^{13}$ criavam situações nas quais, de diferentes modos, os súditos do rei se levantavam e reivindicavam mudanças. Crises de abastecimento, altas inflacionárias, quebras de produção, fomes, epidemias, guerras, atraso de soldos militares, variações de ordem fiscal, disputas por espaços locais de poder, disputas pelo controle da mão-de-obra, dentre muitas outras situações, eram estopins de protestos que acabavam por, freqüentemente, beirar os limites das reciprocidades estabelecidas entre monarca e súditos que, na colônia, alicerçavam as bases da nação portuguesa.

Quando isso ocorria, no entanto, a tendência era do protesto eclodir voltando-se contra os representantes locais do poder real (governadoresgerais, capitães-generais, juizes, fiscais, etc.), preservando e até mesmo reforçando a figura do monarca. Falava-se em "Viva el Rei, morra o mau governo", e assim tais movimentos se revestiam do caráter de instrumentos de negociação entre monarca e súditos, cuja resolução era uma reafirmação dos laços que os unia. ${ }^{14}$ Mesmo quando adquiriam maior radicalismo e incidência e, consequentemente, a agudizavam os sensos de identidades a eles ligados - sobretudo a partir do início do século XVIII, quando da rápida e profunda reconfiguração da dinâmica colonial portuguesa acarretada pela descoberta das primeiras jazidas de ouro em território americano - não se vislumbra a possibilidade dos protestos construírem quaisquer projetos consistente de ruptura do estatuto colonial.

Mantida e reforçada a autoridade metropolitana, no início do século XVIII a crescente importância política e econômica atribuída, no conjunto dos domínios portugueses, à "Província do Brasil, como vulgarmente hoje se chama", cada vez mais sinônimo de "América", 15 fazia com que a identidade luso-americana ganhasse contornos cada vez mais nítidos. Um de seus suportes mais notórios está no campo da História, que, nesta época, começava a apontar para consistentes formulações que progressivamente se afastavam do domínio da crônica e que agora tinham no espaço colo- 
16

Denis Antônio de Mendonça Bernardes. "Genealogia, história e propriedade: integração e ruptura. Um estudo sobre a capitania de Pernambuco. 1748-1817". Paper apresentado no Seminário Internacional Brasil: de um império a outro (1750-1850), realizado no Departamento de História da Universidade de São Paulo, setembro de 2005 (agradeço ao autor a gentileza de me autorizar a citação).Também Íris Kantor - Esquecidos e renascidos: historiografia acadêmica luso-americana (1724-1759). São Paulo, Hucitec, 2004

17

Souza, "0 nome do Brasil", cit., p.80-81.

18

Bernardes, "Genealogia, história e propriedade...", cit., p.15.

19

Kantor - Esquecidos e renascidos..., cit.;

Jancsó. "Independência, independências", cit. nial o centro de suas atenções. Elaboradas por portugueses da América, tais formulações relacionavam-se com reivindicações por títulos e cargos conferidos pelo monarca e necessariamente fundamentados em serviços prestados e antecedentes favoráveis, mas por certo também carregavam consigo um senso de identidade nada desprezivel, ainda que acomodado e organicamente inserido no bojo da nação portuguesa. ${ }^{16}$ Assim, vemos que a História da América portuguesa (1730), de autoria de Sebastião da Rocha Pitta, focada na região "que se chamou América, por Américo Vespúcio, e ultimamente Brasil", faria seu autor merecer, segundo o cronista da Casa de Bragança e Examinador das Três Ordens Militares Dom José Barbosa, "o título do novo Colombo, porque com o seu trabalho e com o seu estudo nos soube descobrir outro mundo novo no mesmo descoberto". 17 Reproduzindo as feições básicas do substrato identitário português na colônia, Domingos Loreto Couto escreveu seus Desagravos do Brasil e glórias de Pernambuco (1757), clara expressão de uma identidade que, ao mesmo tempo em que assinalava diferenças e singularidades entre portugueses, "não busca a ruptura, mas a integração".18

No entanto, se em espaço colonial as expressões de singularização aumentavam, e tendiam, contraditoriamente, a agudizar e acomodar distinções, bem como reiterar as bases da nação portuguesa, será o esforço dirigido de fortalecimento desse mesmo poder que, também a partir de meados do século XVIII, conferirá uma maior clareza à idéia de especificidade dos portugueses da América e, portanto, de uma identidade lusoamericana. 0 conjunto de políticas reformistas levadas a cabo durante os reinados de D. José I (iniciado em 1750) e D. Maria I (iniciado em 1777), que visavam minimizar a persistente desvantagem da posição portuguesa no cenário europeu de competição política e econômica da época, partia de uma premissa básica: o reconhecimento de uma especificidade dos espaços coloniais americanos no conjunto do Império, tidos como passiveis de, mediante uma exploração mais racionalizada, alavancar a recuperação portuguesa. Ora, diante dessa premissa, tais espaços - ou "os Brasis", como ainda era costume se falar - tinham sua inorganicidade esvaziada aos olhos dos dirigentes metropolitanos, que passaram a tratá-los, efetivamente, como uma unidade. ${ }^{19}$ Os Brasis, o Brasil, ou a América, seriam a contraparte mais importante de esforço concentrado envolvendo todos os súditos do rei e que, em última instância, visava "o bem comum" da nação portuguesa.

É aqui que a regra geral, de ausência de conteúdos políticos nas identidades coletivas em vigência no universo luso-americano - no tocante, claro, àquelas articuladas pela nação portuguesa - começa a se transformar. 0 seu ponto de partida é o desenvolvimento de contradições presentes no universo colonial, de modo a criar possibilidades de que a pluralidade que the era inerente pudesse, efetivamente, se traduzir em incompatibilidades, resultando na desarmonia do sistema de relações que até então integravam as diferentes identidades coletivas. Quando isso começa a ocorrer, tais identidades denunciam abalos estruturais na ordem instituída, e passarão a colaborar para o seu aprofundamento na medida em que não apenas denunciam, mas também operacionalizam a desarmonia.

Na segunda metade do século XVIII, o impacto do reformismo ilustrado português na América impôs reordenamentos de vária ordem nas relações de poder vigentes no interior do Império. Por ora, basta-nos destacar que nenhuma dessas reações se fez sentir em termos de respostas diretas e contrárias às políticas metropolitanas de modo a sustentarem 


\section{0}

Sobre o movimento, vide Kenneth Maxwell - A devassa da devassa. A Inconfidência Mineira: Brasil e Portugal, 1750-1808. 2a .ed. Rio de Janeiro, Paz e Terra, 1978; João Pinto Furtado. "Uma república entre dois mundos: Inconfidência Mineira, historiografia e temporalidade". Revista Brasileira de História v.21, n.42, 2001, p.343-363.

\section{1}

Roberta G. Stumpf - Filhos das Minas, americanos e portugueses: identidades coletivas na capitania das Minas Gerais. São Paulo, FFLCHUSP, 2001 (mestrado).

\section{2}

Dai a necessidade que um dos principais estadistas portugueses do reformismo, o então Ministro e Secretário de Estado da Marinha e Dominios Ultramarinos D. Rodrigo de Sousa Coutinho, tinha de evocar, no último lustro do século XVIII, o "inviolável e sacrossanto princípio da unidade, primeira base da monarquia, que se deve conservar com o maior ciúme, a fim de que o Português nascido nas quatro partes do mundo se julgue somente português, e não se lembre senão da glória e grandeza da monarquia a que tem a fortuna de pertencer, reconhecendo e sentindo os felizes efeitos da reunião de um só todo composto de partes tão diferentes que separadas jamais poderiam ser igualmente felizes". "Memória sobre o melhoramento dos domínios de Sua Majestade na América" (1797 OU 1798), Publicada por Andrée Mansuy D. Silva (dir.) - D. Rodrigo de Souza Coutinho: textos políticos, econômicos e financeiros (1783-1811). Lisboa, Banco de Portugal, 1993, t.II, p.47-66.

\section{3}

Luis Villalta. "O que se fala e o que se lê: língua, instrução e leitura"; István Jancsó. "A sedução da liberdade: cotidiano e contestação política no final do século XVIII." Ambos História da vida privada no Brasi, cit., p.331-385 e p.387437, respectivamente. Também Marco Morel - Cipriano Barata na sentinela da liberdade. Salvador, Academia de Letras da Bahia/ Assembléia Legislativa do Estado da Bahia, 2001, parte 1. projetos viáveis de contestação aberta e superação da autoridade do rei. Porém, o acirramento da exploração colonial tendeu, em diversos momentos, a agudizar situações ordinárias daquele universo e produzir manifestações que, sobretudo a partir do último quartel do século XVIII, encontrariam possibilidades históricas de portarem conteúdos políticos cada vez mais violentos e inovadores.

Refiro-me à inserção da América portuguesa no movimento geral que se convencionou chamar de "crise do Antigo Regime". Sem me deter numa caracterização geral de tal processo, gostaria de salientar que uma das faces mais visiveis dessa inserção é a disponibilização, aos portugueses da América que, em fins do século XVIII, por quaisquer motivos encontrassem razões de manifestar publicamente seus descontentamentos, de exemplos históricos de ruptura de espaços coloniais com suas respectivas metrópoles, bem como de supressão radical de estruturas do Antigo Regime. Seguindo uma seqüência cronológica, tornaram-se conhecidos no mundo português os acontecimentos das treze colônias inglesas da América (1776), da Revolução Francesa (1789) e da colônia francesa de Saint-Domingue (1791). Dois deles, convém destacar, ocorridos em espaço americano.

Observemos, então, um caso eloqüente de atribuição, na América portuguesa, de conteúdos novos a identidades coletivas de natureza tradicional: a voz dos conspiradores de Minas Gerais de 1788-1789 e de suas testemunhas. 20 Nela, os envolvidos são "filhos de Minas", "naturais de Minas" e também "filhos da América"; a terra é o "País de Minas", "a capitania", "o continente", mas, principalmente, "a América" ("Brasil" é termo raro, via de regra empregado por integrantes de alguma esfera da administração imperial). ${ }^{21}$ Nesse ponto, América possui três sentidos: a "região de Minas", a "América portuguesa" e, evidentemente, a "América do Norte", onde doze anos antes ocorrera um movimento que, em termos de conteúdos, forneceu os mais espessos subsídios ao vago e confuso programa dos conspiradores de Minas. Não obstante, um programa que falava em "república", "América", deposição de autoridades reais e inauguração de uma nova ordem. Se lembrarmos que no final do século XVIII a América portuguesa conhecia contornos de um significativo mercado interno, e que o reformismo estabelecera com bastante clareza que o Brasil era, por excelência, uma unidade diferenciada de complementação dos desígnios metropolitanos, compreendese por que uma idéia de América começava a fazer sentido, para os próprios colonos, não apenas como referência geográfica geral, mas também como espaço de atuação e identificação política. Uma política que, finalmente, começava a extrapolar, ainda que em contornos mal-definidos, os limites das reciprocidades estabelecidas entre monarca e súditos. 22

Essa politização das identidades coletivas no universo luso-americano, vislumbrada ademais em outras situações e generalizada no bojo de um processo de sensivel e progressivo alargamento, na colônia, dos espaços públicos de discussão política, ${ }^{23}$ conhecerá novo impulso com o colapso que se abateu sobre a metrópole portuguesa em 1807. Incapaz de oferecer resistência aos exércitos franceses, o príncipe regente D. João, sua Corte e mais alguns milhares de pessoas rumaram para o Brasil, instalando-se no Rio de Janeiro com a intenção de, dali, reerguer o debilitado Império.

Nesse momento, inicia-se um duplo movimento com fortes implicações para o plano das identidades. Em primeiro lugar, com o disseminado reconhecimento de que a crise política que se abatia sobre o Império 
chegara ao auge, e valendo-se de novas circunstâncias advindas da instalação da Corte no Rio de Janeiro - como a criação da Imprensa Régia no Brasil e a possibilidade da participação mais direta dos súditos americanos nos negócios da Corte - as discussões políticas conhecerão um verdadeiro boom, tornando-se mais públicas, corriqueiras e socialmente abrangentes. Em segundo lugar, com o centro gravitacional da nação portuguesa deslocado da Europa para a América, esta não apenas tinha sua posição preeminente consolidada, mas também tornava-se uma idéia política nodal para a ulterior manutenção dos alicerces da nação portuguesa. 0 processo de politização das identidades coletivas no espaço luso-americano acompanha esse movimento.

Entretanto, o que se observa nos anos que imediatamente se seguem à transferência da Corte para o Rio de Janeiro, além de uma profunda reestruturação das bases sobre as quais assentavam as relações entre Portugal e a América portuguesa - o fim do tradicional esquema de complementariedade entre metrópole-colônia, a equiparação do estatuto político entre as duas partes, a extinção do projeto de monopólio comercial, a definição de uma aliança umbilical entre Portugal e a Grã-Bretanha - será uma cada vez mais complexa e conflitiva coexistência, no interior da nação portuguesa, entre projetos e alternativas de futuro que, além de se expressarem em identidades coletivas cada vez mais fluidas, terá em tais expressões armas políticas de transformação da realidade. Um panorama permeado de fissuras, cujo agravamento conduzirá a uma situação na qual a pretendida unidade daquele corpo torna-se cada vez mais difícil, e a alternativa da ruptura entre suas partes cada vez mais plausivel. Dentre vários pretextos de discórdia presentes nesse cenário, um dos mais importantes se dava em torno do novo papel a ser desempenhado pelo continente americano na tarefa geral de reforma da combalida unidade portuguesa.

Não detalharei todas as expressões identitárias e seus respectivos conteúdos políticos presentes nesse cenário. Apenas apontarei e analisarei algumas situações nas quais essas expressões se articulam com uma idéia de América, e como tal idéia se configura fundamental para a emergência de uma identidade nacional brasileira. Nesse ponto, é importante destacar que nem tudo o que se passa com o plano das identidades explica-se pela associação com a idéia de América; no entanto, e por motivos gerais que convém explicitar, ela é um dos componentes centrais de organização das redefinições no substrato identitário até aqui analisado.

Creio que o fator fundamental para se entender tal questão está no diagnóstico de que, para o mundo português e seu substrato identitário, a partir de 1808 América começava a deixar de ser uma referência política praticamente restrita aos Estados Unidos da América, e ampliava seus horizontes de modo a abarcar, também, a América espanhola. Como resultado, uma poderosa reconfiguração da identidade política luso-americana que, se até então fora incapaz de gerar, na prática, grandes transformações, agora mostrar-se-ia dotada de uma renovada energia.

0 colapso metropolitano português era parte constitutiva de uma crise que, no plano mais imediato dos fatos, tinha o seu complemento no colapso metropolitano espanhol. Concebendo que da presença militar francesa na península ibérica não poderia resultar outra coisa senão uma extensão política do Império napoleônico, a Corte portuguesa instalada no Brasil logo viu sua leitura da realidade confirmada pelos fatos na Espanha: as abdicações de Bayona, a formação de juntas de governo independentes 
24

João Paulo G. Pimenta - O Brasil e a América espanhola (1808-1822). São Paulo, FFLCH-USP, 2004 (doutorado).
25

Correio Brasiliense n.79, 12/1814. e o início da guerra de resistência no território espanhol. A acefalia da monarquia espanhola, desdobrada em seus domínios ultramarinos, impunha à Corte portuguesa, agora instalada no Rio de Janeiro, uma política especialmente voltada ao continente americano. Na mesma medida, os espaços públicos de discussão política luso-americanos começariam a voltar parcela significativa de suas atenções para o mundo hispânico. Como resultado dessa situação, os acontecimentos da América espanhola passariam a ser atentamente acompanhados no universo luso-americano, exigindo mobilização, oferecendo exemplos e parâmetros de ação, e dando início àquilo que, anteriormente, chamei de "a experiência hispano-americana".24

Em 1808, esses espaços públicos tinham dois de seus principais protagonistas na Gazeta do Rio de Janeiro, periódico oficial da Corte no Brasil, e no Correio Brasiliense, mensário independente editado em Londres. Em meio a documentos, notícias e artigos de opinião (estes mais abundantes no Correio do que na Gazeta), a mais abrangente referência de pertencimento político atribuída aos portugueses é a "nação", concebida em ambos de maneira idêntica: a coletividade formada por todos os súditos do rei de Portugal (no caso, o príncipe regente D. João). E era em prol da unidade dessa nação que os editores dos dois periódicos voltavam seus esforços.

No entanto, para além de semelhanças gerais de propósitos, havia grandes diferenças. Dentre elas, o fato de que, enquanto o Correio Brasiliense publicava sobretudo material relativo ao que se passava nas Américas portuguesa e espanhola, a Gazeta enfatizava, primeiro, os acontecimentos europeus, para só então tratar dos luso-americanos. Nela, a América espanhola pouco aparece, silêncio notável principalmente após a abertura dos processos revolucionários de 1810, pouquissimo abordados. Ou seja: enquanto a Gazeta direcionava seus leitores para a Europa, o Correio os direcionava para a América.

Tal constatação é significativa especialmente porque no Correio, a ênfase em assuntos americanos - incluindo também os dos Estados Unidos - se faz acompanhar de uma concepção de identidade territorial da América portuguesa que, se não é de início capaz de configurar uma idéia política de um Brasil independente, logo evoluirá nessa direção. Assim, por exemplo, lemos em 1814 que

"a extensão de território, a riqueza de produções, e a vantagem da posição Geográfica, com que a Providência se dignou abençoar o Estado do Brasil, ministram a seus habitantes os meios não só de gozar de todas as comodidades da vida, mas de adquirirem riquezas, e chegarem a grande ponto de prosperidade, se por meio do comércio externo, souberem tirar partido de todas as circunstâncias favoráveis".25

Nesse ponto, o Correio revela-se portador do pensamento monárquico-reformista típico da segunda metade do século XVIII, que valorizava uma idéia de Brasil como unidade, complementar a Portugal. Se essa idéia fora consagrada com a transformação do Rio de Janeiro em sede da Corte, foi somente em 1815 que ela obteve reconhecimento oficial formal, com a criação do Reino Unido de Portugal, Brasil e Algarve. Na carta de lei de 16 de dezembro daquele ano, a equiparação de estatuto entre Portugal e Brasil era justificada, nas palavras do príncipe regente, pela

"importância, devida à vastidão, e à localidade dos Meus Domínios da América, à cópia e a variedade dos preciosos elementos de riqueza que eles 
Publicada pela Gazeta do Rio de Janeiro n.03, 10/01/1816.

\section{7}

Analisei a questão em Estado e nação no fim dos impérios ibéricos no Prata (1808-1828). São Paulo, Hucitec/Fapesp, 2002.

\section{8}

Carta de Heliodo Jacinto d'Araujo Carneiro a Thomaz Antônio Vilanova Portugal, 20/11/1817 de Março de 1818 (Arquivo Histórico do Itamaraty, "Documentos avulsos").
29

Parecer sobre a conservação de D. João VI no Brasil, de Rodrigo Pinto Guedes (Arquivo Histórico do Itamaraty, "Documentos avulsos"). em si contém; e outrossim reconhecendo quanto seja vantajosa aos meus fiéis Vassalos em geral, uma perfeita união, e identidade entre os Meus Reinos de Portugal, e dos Algarves, e os Meus Domínios do Brasil, erigindo estes àquela graduação e categoria politica, que pelos sobreditos predizados Ihe deve competir".26

A atribuição de uma identidade territorial à América portuguesa27 integrava o cenário mais amplo de elaboração, da parte do governo de D. João, de uma política de Estado que tinha suas vistas voltadas para o continente americano, sobretudo para a América espanhola. Acompanhamento circunstanciado de tudo o que nela se passava, cuidados com as fronteiras do Brasil e vigilância sobre espanhóis que cruzavam-nas, estabelecimento de cuidadosas e estratégicas relações diplomáticas com os governos independentes que iam surgindo nos vice-reinos hispânicos e intervenções militares, em duas ocasiões, na Província Oriental do Rio da Prata, eram demonstrações de tal política. Uma política conduzida em meio a uma conjuntura na qual o fato essencial era: a América espanhola parecia caminhar, a passos seguros, rumo à independência da Espanha. Em 1818, um conselheiro real recomendava a D. João "de modo algum provocar os Revolucionários de Buenos Aires [...], pois o maior paradoxo político que hoje se possa imaginar é haver quem queira supor que o vasto Continente da América do Sul se tornará ainda Colônia da Europa". Argumentava que "queiram ser ou sejam independentes os Povos vizinhos ao Brasil não é um motivo para se thes declarar uma guerra aberta: pelo contrário [...]. Os aliados natos do Brasil hão de ser sempre os Americanos do Sul e mesmo os do Norte."28 Na mesma linha e pela mesma época, outro conselheiro, defendendo a permanência do rei no Brasil a despeito das reivindicações para que, com o término da guerra peninsular, ele e sua Corte retornassem à Europa, afirmava: "para que o Brasil esteja a coberto das forças da Europa bastar-Ihe-á a aliança dos seus vizinhos do Sul, e do Norte". Propunha a formação de "alianças com os Estados circunvizinhos, cuja necessidade, e utilidade são recíprocos" e, expressamente, a constituição de uma "Liga Americana [...] composta dos Estados Unidos, do Reino ou Estado independente do México, do Brasil, do Reino Americano Meridional e de outros Estados soberanos, porém menores, conforme convier à vista da Carta geográfica, a que devem ser os interpostos dos Reinos, e Estados maiores". 29

Assim, a identidade luso-americana emergia ao longo das primeiras duas décadas do século XIX esboçando conteúdos políticos cada vez mais fortes. Português da América passava a ser uma distinção especial dentro da nação portuguesa, na medida em que identificava um súdito de acordo com um espaço de atuação política que agora era, ao menos segundo os objetivos da Corte, o espaço central de definições do futuro da monarquia.

Não obstante tratar-se de uma perspectiva bastante ampla e disseminada no mundo português, a centralidade política da América não era unânime. A insistência de D. João e de sua Corte em se manterem na sua nova sede causava constrangimentos e acentuava descontentamentos, sobretudo entre portugueses peninsulares. Tais descontentamentos, além de agravarem o quadro geral de persistentes dificuldades que o governo joanino tinha de enfrentar em busca da manutenção da unidade da nação portuguesa, acentuavam e problematizavam o senso de distinção entre americanos e europeus. Serão esses mesmos descontentamentos que 
levarão à eclosão da revolução constitucionalista do Porto, um movimento que, pretendendo reformar a unidade portuguesa limitando e normatizando os poderes do monarca por meio de uma assembléia e de uma Constituição, logrará o retorno da Corte a Lisboa, definirá a operacionalidade política da divisão entre europeus e americanos, e oferecerá poderosos argumentos ao projeto de independência do Brasil. Um projeto que, desde então, começa a surgir no bojo do próprio constitucionalismo, e a partir de interesses politicos e econômicos em torno da permanência do príncipe D. Pedro no Brasil e da manutenção do Rio de Janeiro como sede do poder.

0 meu argumento central pode, então, ser sumarizado da seguinte forma: nos quatorze anos que antecedem a independência, há uma reconfiguração de uma identidade luso-americana anteriormente já existente, agora progressivamente reforçada, politizada e cristalizada pela transformação da América em sede da monarquia. Os fundamentos de tal identidade não só eram plenamente compatíveis com a pluralidade identitária que, tradicionalmente, alicerçava a nação portuguesa, como também pareciam reforçar a perspectiva de complementaridade de espaços segundo os ditames do Reformismo llustrado. No entanto, será nessa mesma identidade que, cada vez mais, os acontecimentos políticos encontrarão um locus de definição de um projeto de viabilização política da América portuguesa como independente de Portugal. Tal movimento se valerá do brutal alargamento dos espaços públicos de discussão política, sobretudo após os decretos de liberdade de imprensa lavrados pelas Cortes constituintes de Lisboa e pelos embates entre representantes de províncias da América e de províncias da Europa que, confrontados em discussões parlamentares corriqueiras, acabarão por agudizar o senso de diferenciação entre dois grupos que, até então, não eram incompatíveis entre si. Por outro lado, tal identidade [luso-americana] só pôde se tornar um elemento crucial de definições porque conjugou-se com o conjunto de lições históricas oferecidas pela América espanhola que, em 1821, havia se tornado, em muitas regiões, independente de sua metrópole, e que poderia, portanto, contribuir para que uma outra América - a portuguesa - seguisse o mesmo caminho.

Nos anos de 1821 e 1822, todas essas definições se processam seguindo a lógica da coexistência de identidades, muitas vezes indeterminadas e pouco claras. Se em 1808 o Correio Brasiliense entendia por "brasiliense" simplesmente o português nascido no Brasil, em fevereiro de 1822 a coisa era mais complicada. Afirmava que, até aquele momento, tinha defendido a união entre Portugal e Brasil acreditando que posições contrárias provinham somente "de algumas pessoas inconsideradas no Brasil, que desejavam a separação dos dois países [...], não nos ocorrendo sequer a possibilidade que nos portugueses europeus pudessem existir essas idéias de desunião". No entanto, constatando que, na verdade, "as coisas vão muito contrário, e que é entre os portugueses e alguns brasileiros, e não entre os brazilienses que se fomenta e se adotam medidas para essa separação", procede ao seguinte esclarecimento:

"chamamos Braziliense, o natural do Brasil; Brasileiro, o português europeu ou o estrangeiro, que lá vai negociar ou estabelecer-se; seguindo o gênio da língua portuguesa, na qual a terminação eiro denota a ocupação; exemplo sapateiro o que faz sapato; ferreiro o que trabalha em ferro; cerieiro o que trabalha em cera; brasileiro o que negocia em brasis ou gêneros do Brasil, etc; por outra parte o natural da Bahia, bahiense e 
30

Correio Brasiliense n.165, 02/1822.

31

Pimenta - Estado e nação..., cit., p.189-190.

32

Revérbero Constitucional Fluminense n.11, 22/01/1822.

33

Correio do Rio de Janeiro n.26, 09/05/1822.

34

Correio do Rio de Janeiro n.80, 19/07/1822.

35

Correio do Rio de Janeiro extra n.03, 21/09/1822.

36

Correio Brasiliense n.170, 07/1822; trecho publicado também pelo Correio do Rio de Janeiro n.158, 21/10/1822. não bahieiro. A terminação em ano também serviria para isto; como por exemplo de Pernambuco, pernambucano; e assim poderíamos dizer brasiliano; mas por via de distinção, desde que começamos a escrever este Periódico, limitamos o derivado brasiliano, para os indígenas do país, usando do outro braziliense, para os estrangeiros e seus descendentes ali nascidos ou estabelecidos; e atuais possuidores do pais". ${ }^{30}$

Ora, o esforço do Correio demonstra uma agudização no senso de distinção entre portugueses do Brasil e de Portugal, mas também uma dificuldade de distingui-los em torno de posições políticas. Assim, se em 1821 circulara no Rio de Janeiro um outro periódico auto-intitulado brasiliense - o Despertador Brasiliense - em 1822 a Malagueta, falava, simultaneamente, em "habitantes do Brasil", "Europeus Brasileiros", "Luso-brasileiros", "Nossa Família Luso-Brasileira", o Brasil como "parte do Império Português" e ao "nosso Caráter Nacional Luso-Brasileiro".31

No entanto, as distinções evoluiam. Clamando contra posições das Cortes constituintes de Lisboa, que muitos acreditavam defender uma "recolonização" do Brasil, o Revérbero Constitucional Fluminense sintetizava vários elementos das mutações identitárias em curso: concebia uma identidade do Brasil associada a uma idéia política (constitucional) de América (incluindo os Estados Unidos), e opunha a esta identidade Portugal; mas encontrava dificuldades em achar a palavra que melhor a designasse:

"A Revolução de Portugal [...] oferecia duas combinações diferentes [...] Ou o Rei se conservava no Brasil, ou voltava para Portugal. Se ficava preferindo um Mundo na América a uma Província na Europa, era impossível que o Brasil, situado no centro das Constituições Americanas, comunicando-se diariamente com povos constituídos, e contratando com homens Constitucionais, tendo por estrela polar os Estados Unidos, que muito alto colocaram o farol para escapar às vistas nos Povos vizinhos, se pudesse subtrair a este vértice de influências[...]. Dirão talvez que damos a denominação genérica de Brasil às únicas Províncias do Rio de Janeiro, Minas, São Paulo, e Rio Grande, que só por ora estão ligadas. Nós faríamos uma injustiça a todo o resto da Familia Brasiliense se o acreditássemos dissidentes do partido da Honra, e da Glória Nacional"32

Outro periódico, o Correio do Rio de Janeiro afirmava, em maio de 1822, que "o sistema europeu é e sempre foi dominar Colônias", e que "um sistema Europeu motiva outro Americano, e o choque destes dois sistemas pode levar ao abismo a Nação Portuguesa". 33 Dois meses depois, prognosticava que "o Brasil, parte integrante do novo mundo, País da Liberdade, não ficará aquém da linha de conduta que tem seguido a maior parte da América", pois "os Portugueses, ou Luso-Brasilienses, não cedem no amor da glória, e da Liberdade, a nenhuma Nação do mundo". 34 E, finalmente, em setembro, que "o Deus da Natureza fez a América para ser Independente, e Livre: 0 Deus da Natureza Conservou no Brasil o Príncipe Regente para ser Aquele, que Firmasse a Independência deste vasto Continente."35

Voltando ao Correio Brasiliense, vemos que ele afirmava, já em julho de 1822, que "a causa Americana está decidida, e acabada nela a dominação Européia". Regozijava-se seu editor de ter vivido "quanto basta, para morrermos satisfeitos, havendo testemunhado a liberdade geral daquela parte do Mundo, em que nascemos"36. Não destoavam tais palavras 
37

Rio de Janeiro, 01/08/1822. Publicada pelo Correio do Rio de Janeiro n.96, 08/08/1822. daquelas publicizadas em agosto de 1822 pelo futuro imperador do Brasil, numa famosa proclamação aos "Povos deste Reino":

"BRASILEIROS[...]. Encarai, habitantes do Brasil, encarai a perspectiva de Glória, e de Grandeza, que se vos anteolha: não vos assustem os atrasos da vossa situação atual; o fluxo da civilização começa a correr já impetuoso desde os desertos da Califórnia até ao estreito de Magalhães, Constituição, e Liberdade legal são fontes inesgotáveis de prodígios, e serão a ponte por onde o bom da velha e convulsa Europa passará ao nosso continente. Não temais as Nações Estrangeiras: a Europa, que reconheceu a Independência dos Estados Unidos da América, e que ficou neutral na luta das Colônias Espanholas, não pode deixar de reconhecer a do Brasil, que, com tanta justiça, e tantos meios, e recursos procura também entrar na grande família das Nações. Nós nunca nos envolveremos nos seus negócios particulares; mas elas também não querem perturbar a paz e comércio livre, que Ihes oferecemos; garantidos por um Governo Representativo, que vamos estabelecer. Não se ouça pois entre vós outro grito que não seja - UNIÃO - Do Amazonas ao Prata não retumbe outro eco, que não seja - INDEPENDÊNCIA. - Formem todas as nossas Provincias o feixe misterioso, que nenhuma força pode quebrar".37

E assim, ficava definido que o Brasil poderia ser "livre" porque a América toda já o era. Um Brasil que, não obstante ter diante de si a árdua tarefa de construir uma unidade política e territorial, bem como um Estado, uma nação e uma identidade nacional que ainda não se encontravam plenamente definidos, estabelecia, naquele momento, que a condição de sua "liberdade" era ser americano. 